\title{
Indirect choroidal tears at the posterior pole: a fluorescein angiographic and perimetric study
}

\author{
J. C. DEAN HART, V. E. NATSIKOS, E. R. RAISTRICK, AND R. M. L. DORAN \\ From the University Department of Ophthalmology, Bristol Eye Hospita!
}

SUMMARY Retinal fluorescein angiographic and visual field studies were performed on 10 patients who had developed indirect choroidal tears, these procedures being repeated at intervals until the retinal disturbances stabilised. Fluorographic investigations revealed that a transient breakdown of the choroidoretinal barrier to fluorescein dye could be detected in cases investigated within 4 days of injury, and also that the late complication of neovascularisation, producing a serous maculopathy, may resolve and good central vision be retained without recourse to photocoagulation therapy. Patients who had visual field examinations performed within a few days of trauma were noted to have dense central scotomata, but some recovery occurred in most cases, although to a variable degree. Field defects away from fixation corresponded to an extent with areas of posttraumatic pigmentary retinopathy, but in some portions of retina with normal background appearances sensitivity was also noted to be reduced. Scotomata corresponding specifically to choroidal tears or nerve fibre bundle defects were not recorded. Improvement of visual acuity may be expected, except in cases where a choroidal tear has involved the fovea or progressive choroidal neovascularisation led to permanent macular damage.

Indirect choroidal tears at the posterior pole, commonly found in patients who have received severe concussive injuries to the eyeball, are now thought to arise from purely mechanical causes produced by forces generated at the time when a missile impacts against the globe (François and Bonnet, 1976). Splits develop in the choriocapillaris, Bruch's membrane, and sometimes in the pigment epithelium, permitting blood to extravasate into the choroid and the neural layers of the retina (Gass, 1967), but if the retinal pigment layer remains essentially intact a haematoma may form immediately underneath, giving rise to a haemorrhagic pigment detachment (Gitter et al., 1968). These haemorrhages are subsequently absorbed. Pathological studies have shown that breaks in the choroid become invaded by connective tissue elements, and ruptures of the pigment layer are probably sealed by epithelial cells growing inwards from the edges of the tear (Duke-Elder and MacFaul, 1972). The question whether defects of the choroidoretinal barrier adjacent to the tear can be detected by

Correspondence to Mr J. C. Dean Hart, University Department of Ophthalmology, Lower Maudlin Street, Bristol BS1 2LX. means of fluorescein angiographic investigations in the immediate post-traumatic period has, however, received little attention.

A variety of visual field changes have been described in cases noted to have indirect choroidal ruptures. Although scotomata relating to the typical pale, crescentic lesions detected on ophthalmoscopic examination were observed by Neame (1940), most investigators have noted central defects associated with post-traumatic maculopathies (Traquair, 1949; Harrington, 1964). Some workers identified sector field loss which they attributed to nerve fibre bundle disturbances (Harrington, 1964; Maberley and Carvounis, 1977), while others were unable to find any specific pattern of visual field impairment (Reed and Drance, 1972). Maberley and Carvounis (1977) stated that the field disturbances were usually greater than might be expected from signs detected on ophthalmoscopic examination and clearly did not relate to the crescentic lesions alone. Although central scotomata noted in the immediate post-traumatic period in patients developing concussive pigmentary maculopathies may become less dense and paracentral in position (Hart and Frank, 1975), there is some uncertainty whether field defects found in patients with choroidal tears alter with time. 
Table 1 Details of patients with choroidal tears

\begin{tabular}{|c|c|c|c|c|c|c|c|c|}
\hline $\begin{array}{l}\text { Case } \\
\text { No. }\end{array}$ & $\operatorname{Sex}$ & Age & Cause of injury & $\begin{array}{l}\text { No. and position of } \\
\text { tears }\end{array}$ & $\begin{array}{l}V A \text { on initial } \\
\text { examination }\end{array}$ & $\begin{array}{l}V A \text { on final } \\
\text { examination }\end{array}$ & $\begin{array}{l}\text { Residual macular } \\
\text { appearances }\end{array}$ & $\begin{array}{l}\text { Duration of } \\
\text { observation }\end{array}$ \\
\hline 1 & $\mathbf{M}$ & 34 & Assault-iron bar & $\begin{array}{l}1 \text { nasal to macula } \\
1 \text { involving macula }\end{array}$ & $>6 / 60$ & CF & $\begin{array}{l}\text { Choroidal } \\
\text { neovascular } \\
\text { maculopathy }\end{array}$ & 2 years \\
\hline 2 & $\mathbf{M}$ & 20 & Assault-kicked & $\begin{array}{l}1 \text { nasal to macula } \\
1 \text { involving macula }\end{array}$ & $>6 / 60$ & $6 / 36$ & $\begin{array}{l}\text { Choroidal } \\
\text { neovascular } \\
\text { maculopathy }\end{array}$ & 3 years \\
\hline 3 & $\mathbf{F}$ & 22 & Elbow & 1 temporal to macula & CF & $6 / 9$ & Pigmentation & $4 / 12$ \\
\hline 4 & $\mathbf{M}$ & 19 & $\begin{array}{l}\text { Walked into } \\
\text { projecting knob }\end{array}$ & 1 nasal to macula & CF & $6 / 6$ & Normal & $8 / 12$ \\
\hline 5 & $\mathbf{M}$ & 18 & Apple & $\begin{array}{l}1 \text { inferior to disc } \\
1 \text { involving macula }\end{array}$ & CF & $1 / 60$ & $\begin{array}{l}\text { Tear bisecting } \\
\text { macula }\end{array}$ & $18 / 12$ \\
\hline 6 & $\mathbf{F}$ & 15 & Airgun pellet & $\begin{array}{l}1 \text { nasal to macula } \\
1 \text { temporal to macula }\end{array}$ & $1 / 60$ & $6 / 9$ & $\begin{array}{l}\text { Cyst and } \\
\text { pigmentation }\end{array}$ & 4 years \\
\hline 7 & $\mathbf{F}$ & 28 & Shuttlecock & 1 nasal to macula & PL & $6 / 18$ & Cyst & $6 / 12$ \\
\hline 8 & $\mathbf{M}$ & 16 & Hockey ball & 1 inferior to macula & $1 / 60$ & $6 / 12$ & Pigmentation & $4 / 12$ \\
\hline 9 & $\mathbf{M}$ & 38 & Lump of metal & $\begin{array}{l}2 \text { temporal to macula } \\
1 \text { involving macula }\end{array}$ & HM & HM & $\begin{array}{l}\text { Tear bisceting } \\
\text { macula }\end{array}$ & 1 year \\
\hline 10 & $\mathbf{M}$ & 33 & RTA & $\begin{array}{l}1 \text { involving macula } \\
1 \text { inferior to disc }\end{array}$ & $>6 / 60$ & $6 / 6$ & Pigmentation & $2 \frac{1}{2}$ years \\
\hline
\end{tabular}

$\mathrm{VA}=$ Visual acuity. $\mathrm{CF}=$ counting fingers. $\mathbf{H M}=$ hand movements. $\mathrm{PL}=$ perception of light. $\mathrm{RTA}=$ road traffic accident.

Fig. 1 Case 5. Fluorescein angiogram left eye 5 weeks after trauma showing 2 choroidal tears, one below and temporal to the disc, the second bisecting the macula; retinal pigment epithelial disturbances have developed around the disc. VA $6 / 60$

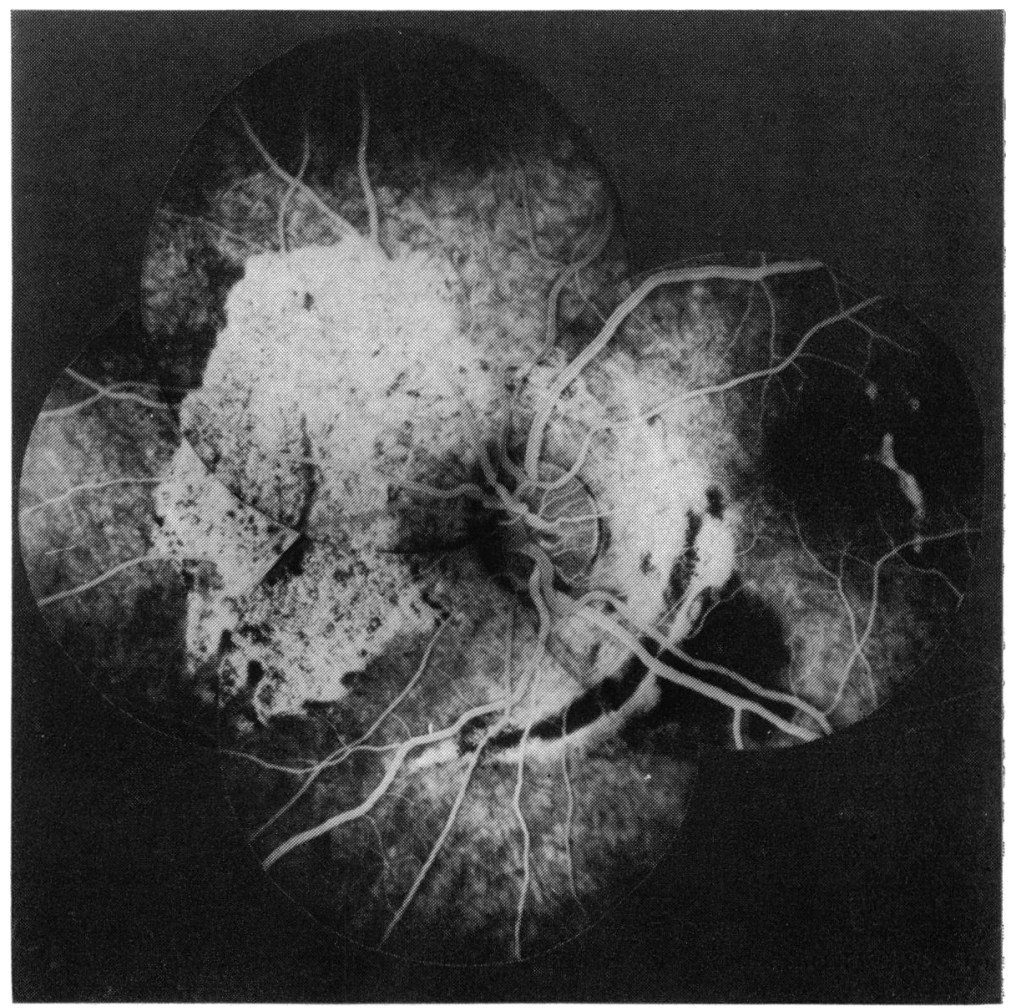


No studies on patients with indirect choroidal tears, in whom both sequential fluorescein angiographic and visual field investigations were performed, have to the best of our knowledge been reported. The findings of such a study form the basis of this communication.
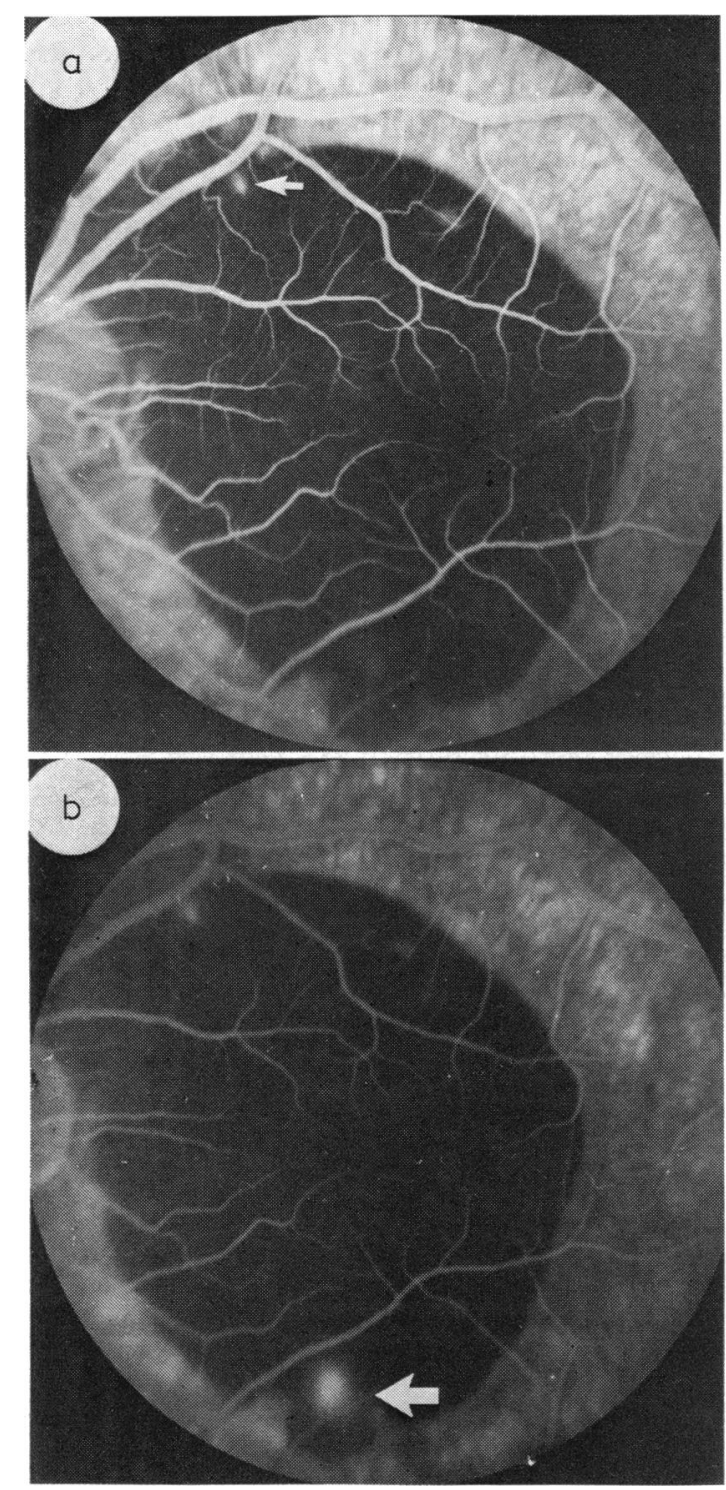

Fig. 2 Case 4. Fluorescein angiogram 2 days after trauma demonstrating (a) in the venous phase fluorescence from a tear appearing through the edge of a subretinal pigment epithelial haematoma above (small arrow); (b) in the residual phase, leakage of dye into the retina inferiorly (large arrow); fluorescence from the tear superiorly has faded. VA 6/60

\section{Materials and methods}

Patients attending hospital with a history of severe blunt mechanical nonperforating ocular injury, found on examination to have indirect choroidal tears at the posterior pole, were referred to our unit for further assessment. A full ocular examination was subsequently performed, which included evaluation of the corrected visual acuity, inspection of the fundus by indirect ophthalmoscopy followed by fluorescein angiographic and detailed Goldmann perimetric studies, both kinetic and static. Follow-up investigations were carried out until the retinal disturbances had stabilised. Only those patients with no

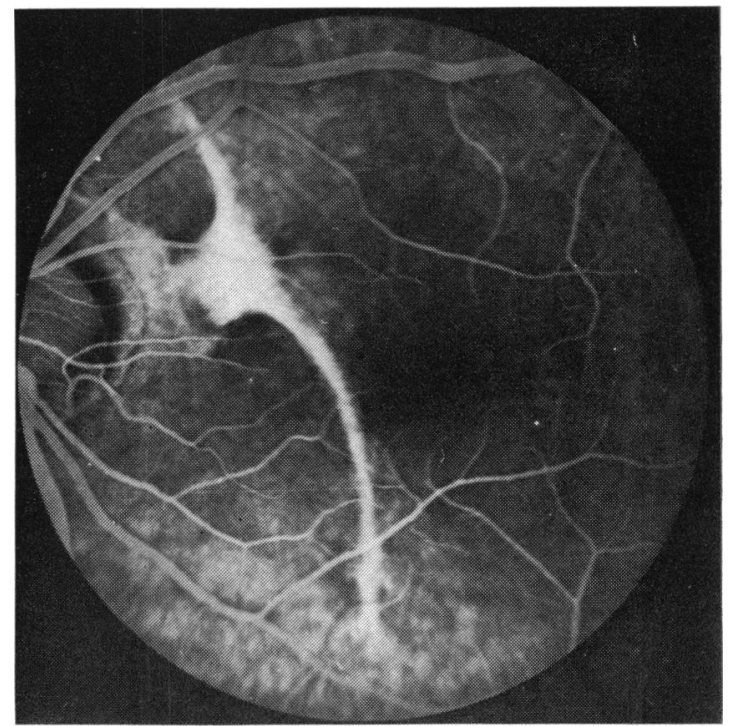

Fig. 3 Case 4. Fluorescein angiogram 8 months after trauma. The choroidal tear is now clearly defined. No leakage of dye into the retina has occurred. VA 6/6

evidence of pre-existing ocular disease who were able to co-operate fully with the programme and attended for follow-up investigations as required were retained in the series.

\section{Results}

Ten patients with indirect choroidal tears at the posterior pole, 7 male and 3 female in the age group 15-38 years, attended regularly for assessment over periods ranging from 4 months to 4 years. All had received uniocular injuries as a result of a wide variety of missiles impacting on the anterior half of the globe (Table 1), except case 10, who developed bilateral lesions after a road traffic accident, one eye 
being so severely damaged that it was enucleated forthwith.

VISUAL ACUITY MEASUREMENTS

Although on initial examination central vision was noted to be severely depressed to $6 / 60$ or less in all
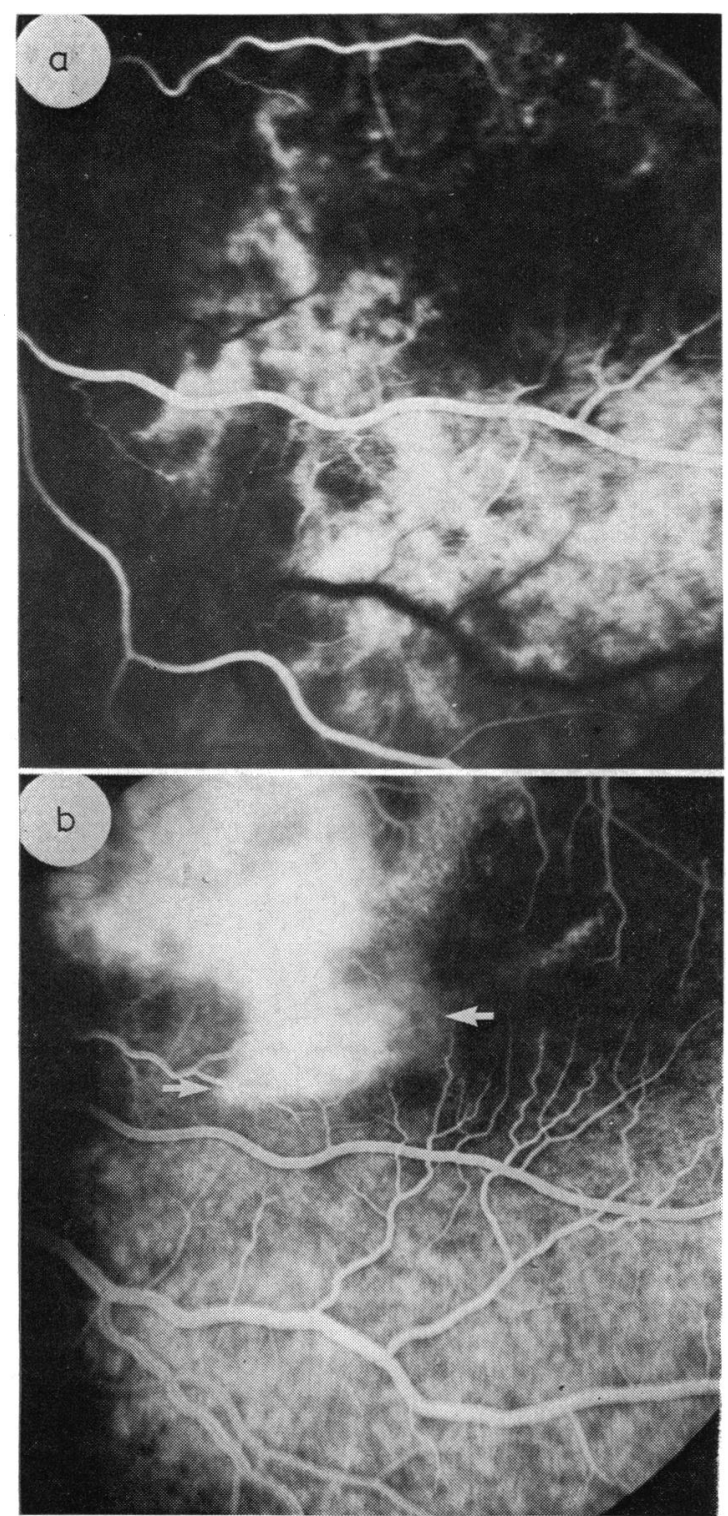

Fig. 4 Case 8. Fluorescein angiogram 4 days after trauma, showing (a) masking of the choroidal fuorescence between the disc and the macula in the arterial phase; (b) staining of retinal pigment epithelium and leakage of dye from a portion of the tear (arrows), late venous phase. VA 6/36 patients, mainly due to impairment of retinal function, acuity eventually recovered to $6 / 18$ or better in 6 . Where it was observed that a choroidal tear had bisected the macula and extensive post-traumatic pigmentary changes appeared at the posterior pole, as in cases 5 (Fig. 1) and 9, no significant improvement in central vision occurred. In 2 cases, 1 and 2 , visual acuity initially improved from less than $6 / 60$ to $6 / 9$ and 6/24 respectively and then deteriorated when subretinal neovascularisation and serous detachment of the macular developed (in case 14 months after injury and in case 218 months later). Neither the presence of a haemorrhagic pigment epithelial detachment involving the macular (seen in

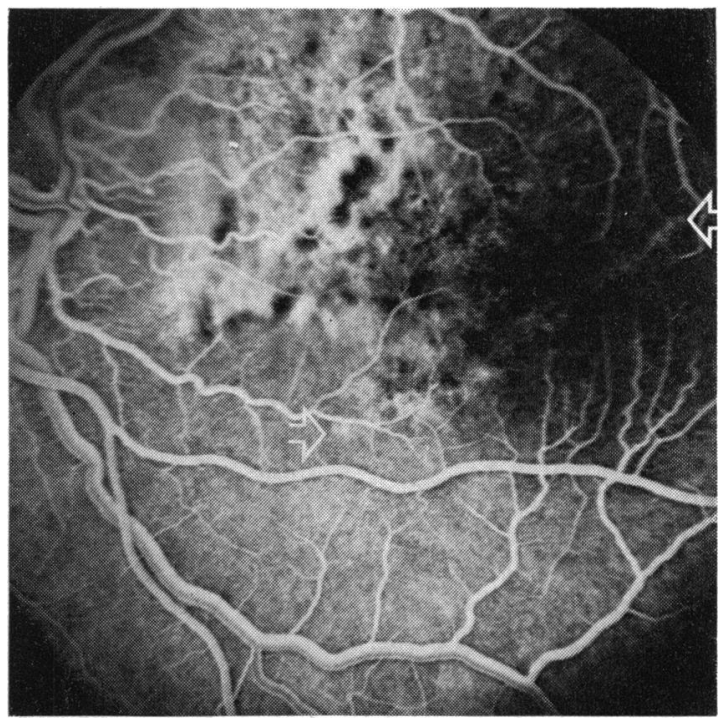

Fig. 5 Case 8. Fluorescein angiogram 7 days after trauma, venous phase. The extent of the tear is defined (arrows); no leakage of dye is apparent from this site and staining of the pigment epithelium limited to the region adjacent to the disc. VA 6/24

cases 3,4 , and 6) nor the location of choroidal tears, except when the fovea was involved, had any apparent bearing on the eventual degree of visual recovery. Visual acuity recovered to $6 / 12$ or better in 4 patients who acquired post-traumatic macular holes or pigmentary maculopathies.

\section{FLUORESCEIN ANGIOGRAPHIC STUDIES}

Early changes

No disorders of the retinal vascular system were observed in the immediate post-traumatic period, and disturbances of the choroidal vessels appeared to be limited to the region of the tears themselves. 
In cases 3 and 4 , where any underlying tear was initially masked by a haemorrhagic pigment epithelial detachment, fluorescein studies performed $\mathbf{2}$ days after trauma showed leakage of dye into the neural layers of the retina at the margins of the haematoma (Fig. 2). These defects of the choroidoretinal barrier, subsequently found to be located close to the extremities of the rupture, resolved without further sequelae (Fig. 3). In case 8, examined
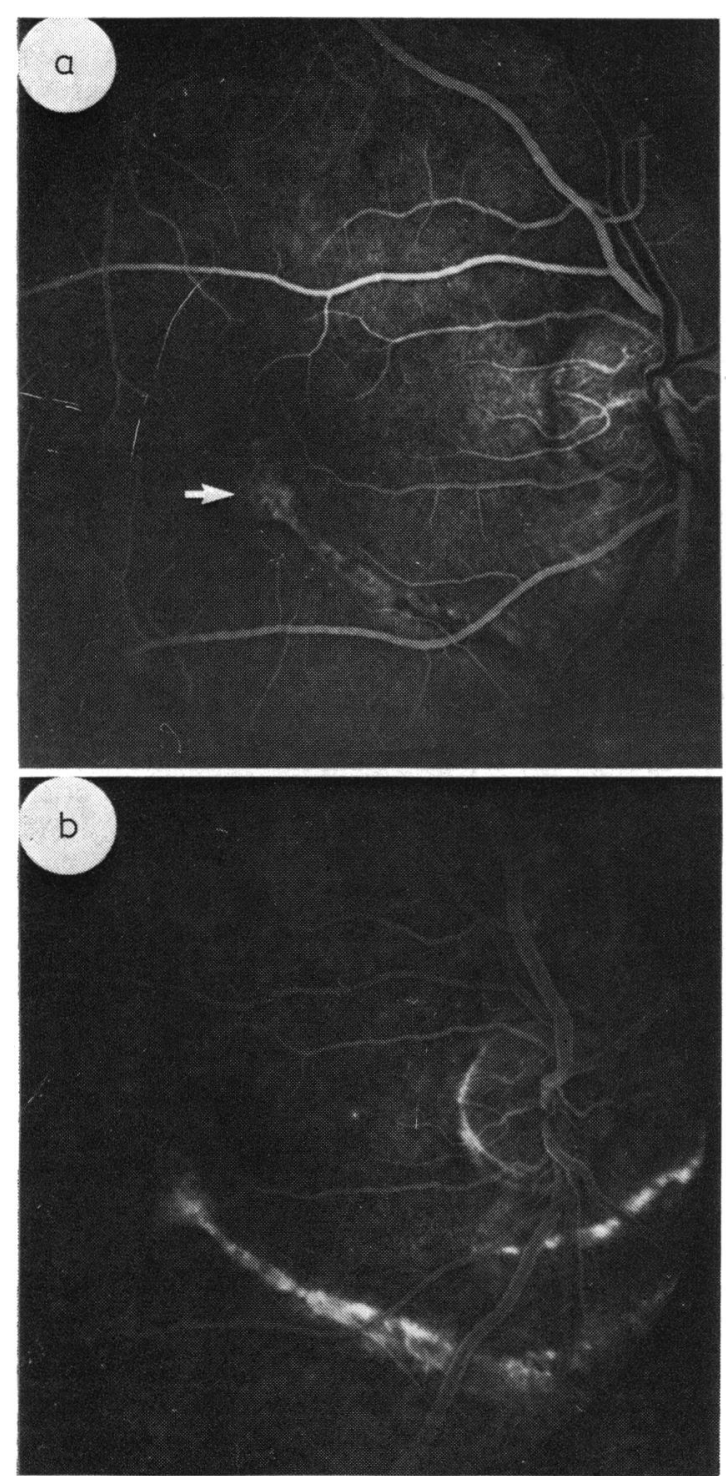

Fig. 6 Case 10. Fluorescein angiogram 4 months after injury, showing two choroidal ruptures with (a) new vessels outlined in the tear adjacent to the macula (arrow); (b) leakage of dye from this site. VA 6/18 within 24 hours of trauma, retinal pallor was noted between the disc and the macula. Fluorescein angiographic studies 4 days after injury revealed marked staining of the retinal pigment epithelium in the opacified zone and leakage of dye from a small tear inferior to the macula (Fig. 4). Three days later barrier function had largely recovered (Fig. 5). Dye studies performed on case 15 days after injury, and on cases 5 and 7 within 6 weeks of injury, failed to show any leakage into the retina.

\section{Late changes}

Investigations performed 3 or more months after injury showed hyperfluorescence in the torn areas, normally maximal in the venous phase, but persisting

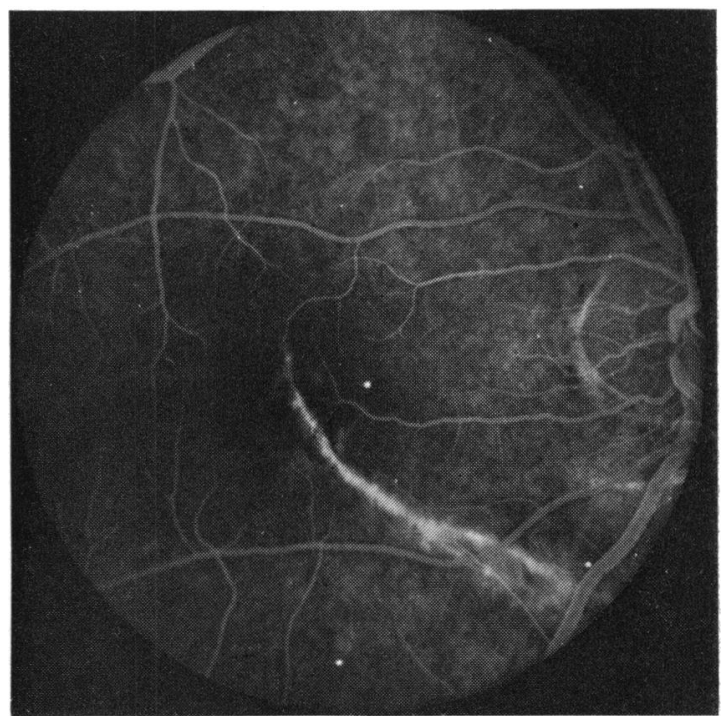

Fig. 7 Case 10. Fluorescein angiogram 6 months after trauma, demonstrating regression of vew vessels. VA 6/9

into the residual phase (Figs. 1 and 3), and studies on 7 patients revealed no leakage of dye into the retinal tissues. In the only eye of case 10 visual acuity improved from counting fingers after trauma to $6 / 94$ months later, but then deteriorated to 6/18. Macular oedema was observed, and fluorescein investigations revealed an area of choroidal neovascularisation arising from a portion of the tear adjacent to the macula, from which site a moderate leakage of dye occurred (Fig. 6). However, apart from a short dose of systemic steroids (prednisolone $15 \mathrm{mg}$ daily for 1 month), no further treatment was given. The macular oedema resolved, and repeat fluorescein angiographic studies carried out 2 months later showed that the new vessels had regressed and the 
choroidoretinal barrier now appeared intact (Fig. 7). This patient's visual acuity eventually recovered to $6 / 6$. In two cases, 1 and 2 , in whom progressive choroidal neovascularisation caused permanent macular disturbances, fluorescein angiographic studies showed the location and extent of the abnormal vessels (Fig. 8). New vessels temporal to the macula were photocoagulated in case 2 , and
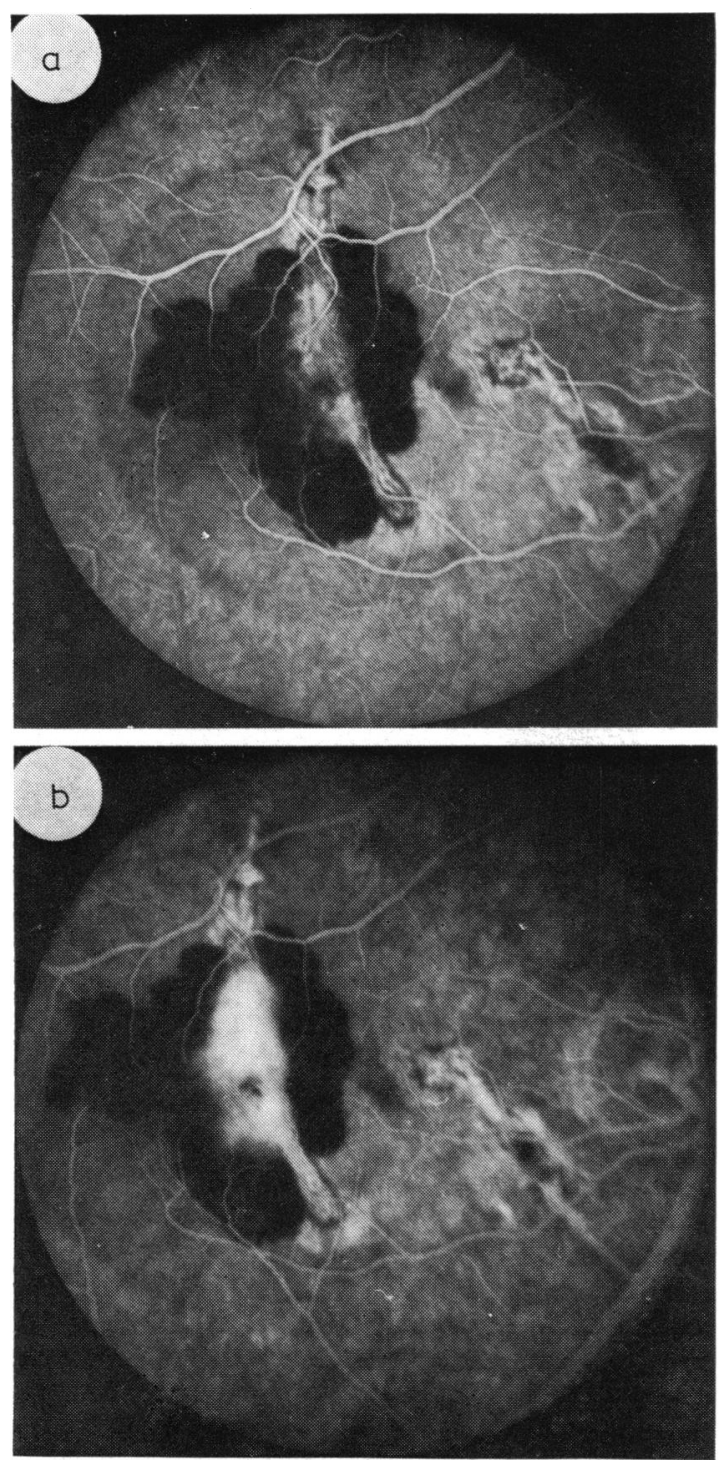

Fig. 8 Case 2. Fluorescein angiogram 18 months after trauma, showing (a) choroidal new vessels arising from a tear adjacent to the macula, with retinal haemorrhages temporally and nasally, and later (b) profuse leakage of dye from the central portion of the tear. VA $6 / 60$ although visual acuity did not improve beyond $6 / 36$ these vessels regressed and no further leakage of dye was subsequently detected.

Fluorescein angiographic studies also highlighted areas of pigmentary disturbance, the extent of which was not always easily identifiable on indirect ophthalmoscopy (Fig. 1).

\section{VISUAL FIELD STUDIES}

All patients seen soon after injury were noted to have dense central or centrocaecal scotomata, but retinal sensitivity at the posterior pole gradually recovered to a variable degree over a period of weeks or months (Fig. 9), deteriorating again only in those patients who developed serous maculopathies. In every case, however, residual defects adjacent to fixation could be found, which remained as permanent sequelae of the ocular trauma. Central scotomata tended to become smaller (cases 5 and 9) and less dense, as in cases 3, 4, 6, 7, and 8 (Fig. 10), and in case 10 small paracentral defects detectable by static perimetry alone were found at the final followup examination (Fig. 11).

We could not identify scotomata which could be specifically related solely to a choroidal tear, either on kinetic or static field testing, nor plot sector defects which might have indicated nerve fibre bundle lesions, although cases 5 and 10 showed baring of the blind spot immediately after trauma. Areas of reduced sensitivity were diffuse rather than focal and more widespread in cases where extensive posttraumatic retinal pigment epithelial clumping and atrophy had occurred. These changes had often developed at some distance from the tear (Figs. 1 and 12). Constriction of the peripheral fields was also noted in a few patients after injury, as in cases 5 and 10 , but some expansion of the fields occurred over a period of time (Fig. 11).

\section{Discussion}

Reports on patients developing concussive maculopathies indicate that adolescents and young adult males form a high percentage of those seen with such injuries (François and Bonnet, 1976). This group runs a major risk of being involved in affrays, industrial accidents, and trauma related to sport. The sex and age pattern is similar for choroidal tears.

Although the spectrum of residual retinal damage is wide in patients who have acquired indirect choroidal ruptures at the posterior pole, permanent macular disturbances were detected on ophthalmoscopy in 9 out of 10 cases examined in this series. Eagling (1974) reported that central vision often recovered in cases developing post-traumatic maculopathies, though progress was slow, and might 


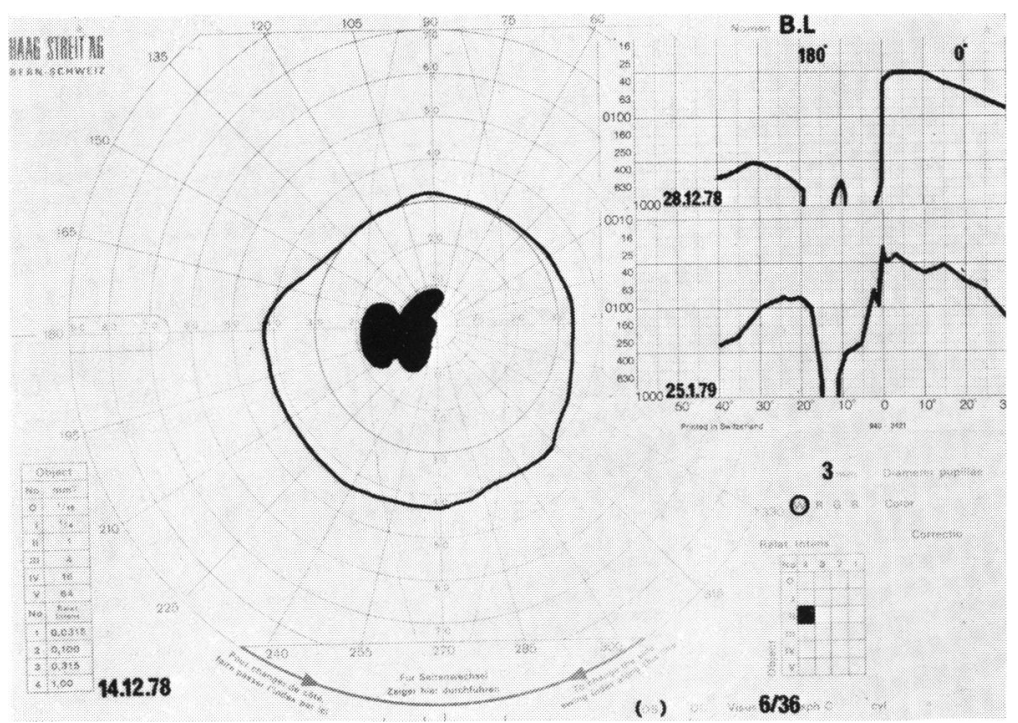

Fig. 9 Case 8. Visual field, left eye, 6 days after trauma. A centrocaecal scotoma is present. Static fields 20 and 48 days after injury (180- $0^{\circ}$ profile) showing recovery of retinal sensitivity in the central area

continue to improve for up to 6 months. François and Bonnet (1976) could not identify any factors on presentation which might be of prognostic value, except that if a choroidal tear involved the fovea the visual acuity remained impaired. Our investigations confirm the above findings.

The precise nature of the early disturbances which develop in the retinal pigment epithelium adjacent to indirect choroidal tears is poorly understood, as few eyes have been studied histologically soon after the traumatic event. Undoubtedly ruptures of the pigment epithelium may occur (Duke-Elder and
MacFaul, 1972), but Yanoff and Fine (1975) stated that, while Bruch's membrane and the choriocapillaris alone or the full thickness of the choroid is ruptured, the overlying retina is not usually found to be involved.

Fluorescein angiographic studies performed by us clearly demonstrated that disturbances of the choroidoretinal barrier can be detected in the immediate post-traumatic period, but that the leaks seal off within a few days. Retinal pigment epithelium has a marked ability to regenerate after a variety of injuries, including grade II traumatic retinal oedema

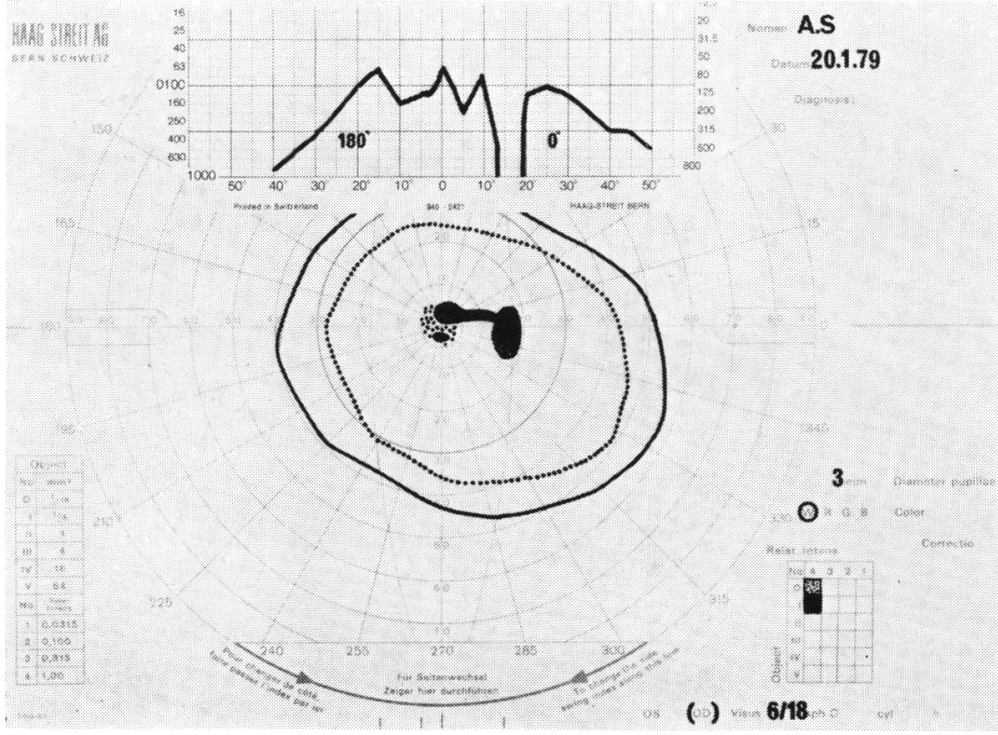

Fig. 10 Case 7. Kinetic and static $\left(180-0^{\circ}\right.$ profile) field changes recorded 5 months after trauma to the right eye, demonstrating a centrocaecal defect 
Fig. 11 Case 10. Showing progressive increase in size of the peripheral visual field 4 months, 6 months and 28 months after trauma. Static field (180-0 $0^{\circ}$ profile) demonstrates residual paracentral defects 28 months after injury

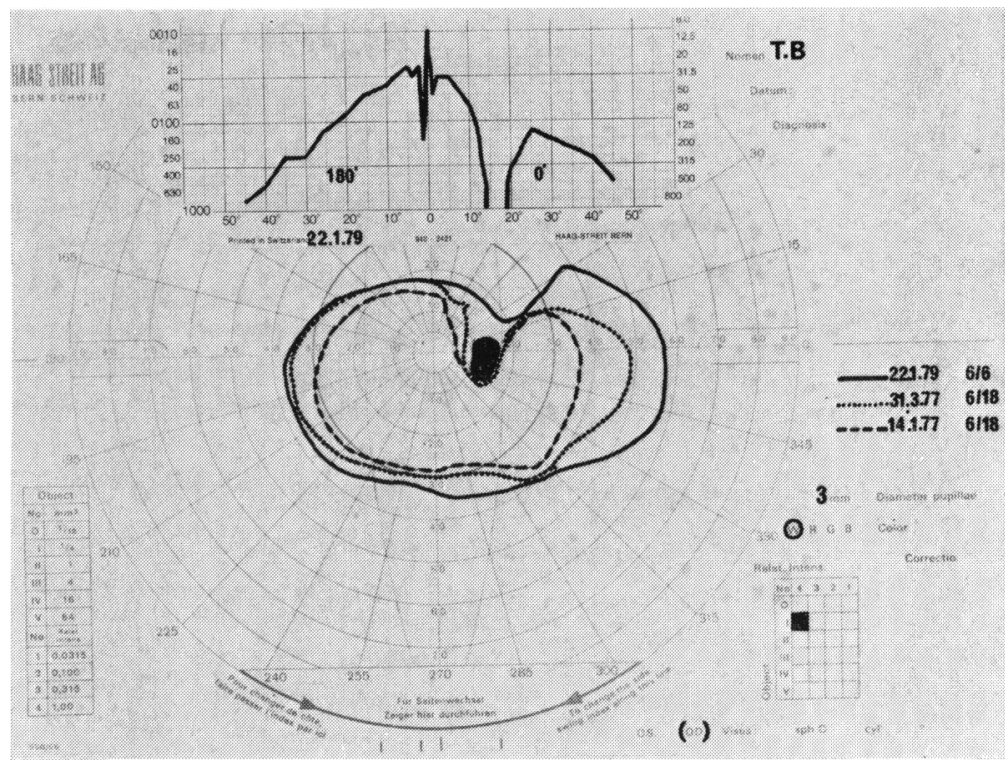

(Hart and Frank, 1975), but we are not aware of any previous reports describing similar changes in patients with choroidal tears.

Delayed breakdown of the choroidoretinal barrier associated with new vessels invading the retina through a choroidal rupture adjacent to the macula was initially reported by Gass (1970). Such disturbances may cause permanent macular changes with severe visual loss, though laser therapy has proved beneficial in some individuals (Fuller and Gitter, 1973). Two cases developing late macular changes have been reported in this series, but exami- nation of our case records of patients with choroidal tears shows that less than $10 \%$ developed this complication. Late leakage of fluorescein dye into the retina following choroidal neovascularisation in a tear adjacent to the macula, which later subsided spontaneously, was described by Smith et al. (1974). The leak they detected was separated from the fovea by a zone of pigmentation, no therapy was instituted, and good vision was retained. On the basis of this report and our findings in case 10 it would seem advisable to withhold photocoagulation therapy in cases where delayed leaks occur, unless definitive
Fig. 12 Case 5. Dense central and paracentral scotomas are present 9 months after injury, which partially correspond to the retinal pigment epithelial disturbances noted on fluorescein angiography (see Fig. 1). Pupil dilated as result of traumatic mydriasis

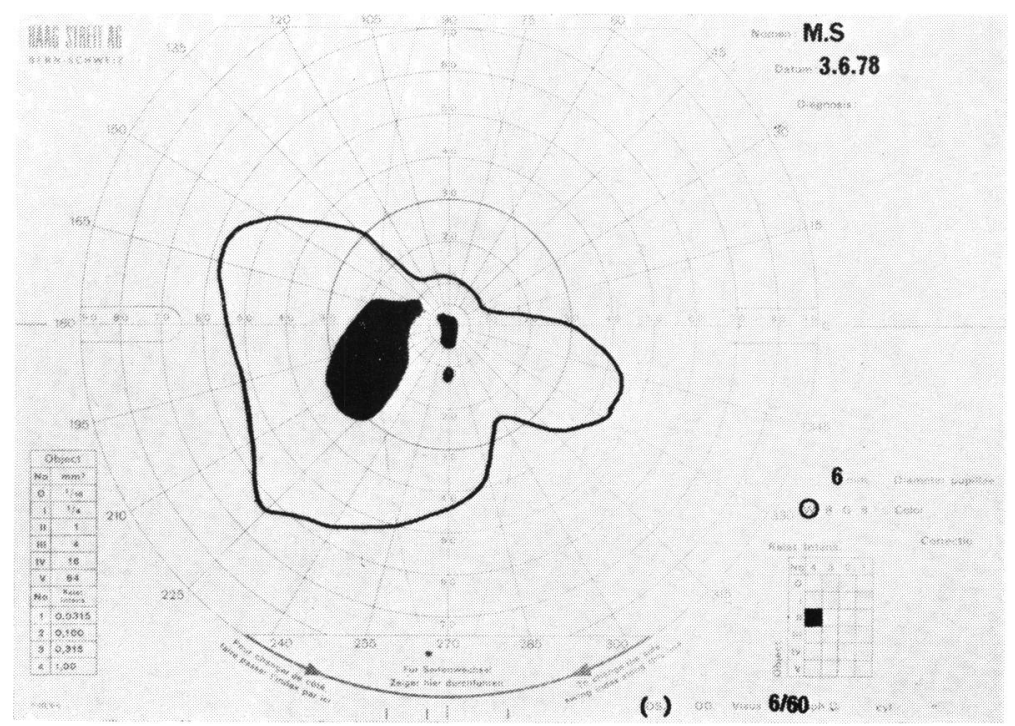


evidence can be obtained of progressive choroida neovascularisation. The role of systemic steroids in treating this condition must remain speculative.

Eagling (1974) suggested that central field analysis was helpful in determining the visual prognosis in patients who had received severe concussive injuries to the eyes, as areas of absolute scotomata, unless due to choroidal haematomata, showed no significant improvement with time. Our findings do not support this statement. All patients examined within a few days of injury in this series were noted to have a dense central scotoma. Although residual field defects were detected in every case seen up to 4 years after injury, on either static or kinetic perimetric testing, the majority of patients regained visual acuities of $6 / 18$ or better.

Visual field defects away from the centrocaecal area were found to be nonspecific in type. The only association found in this study between lesions visible on ophthalmoscopy and field disturbances was that, in areas where post-traumatic pigmentary changes had developed, retinal sensitivity was reduced or absent. We agree with Maberley and Carvounis (1977) that field defects were often larger than might be expected from ophthalmoscopic examination of the fundus, and areas of retina with normal background appearances also showed some evidence of malfunction.

We did not detect in any of our cases definitive evidence of nerve fibre bundle defects. No signs of optic atrophy or changes in the nerve fibre light reflex could be found on red-free fundus photography. It is possible, however, that if a choroidal tear developed adjacent to the disc margin the blood supply to the optic nerve head might then be jeopardised and a sector defect produced. This would, in essence, be an incomplete avulsion of the optic nerve.

It is our impression that the principal disturbances leading to impairment of vision which occur in the retinae of patients presenting with choroidal tears are located in the photoreceptor outer segment and pigment epithelial layers. Such changes may involve large areas. Fragmentation of the photoreceptor outer segments has been noted to occur in primates after concussive injuries to the eyes, as a contre-coup response (Sipperley et al., 1978). Similar changes have been reported in pigs after coup injuries, possibly as a result of mechanical shearing effects (Blight and Hart, 1977), and in these experiments regeneration of the photoreceptor outer segments was observed. If similar changes operate in man, an improvement of the visual fields might well be explained on this basis.

We thank Mr N. L. Dallas, Mr W. Rich, and Mr D. Lyons, who referred patients to this department for assessment, Mr J. Morgan and the Department of Visual Aids, University of Bristol, for photographic services, and Mrs M. Roach for secretarial help.

\section{References}

Blight, R., and Hart, J. C. D. (1977). Structural changes in the outer retinal layers following blunt mechanical injuries to the globe: an experimental study. British Journal of Ophthalmology, 61, 573-587.

Duke-Elder, S., and MacFaul, P. (1972). System of Ophthalmology, vol. XIV, part 1, p. 166. Mechanical Injuries. Kimpton: London.

Eagling, E. M. (1974). Ocular damage after blunt trauma to the eye. Its relationship to the nature of the injury. British Journal of Ophthalmology, 58, 126-140.

François, P., and Bonnet, M. (1976). La Macula, 1st edn., pp. 400-411. Masson: Paris.

Fuller, B., and Gitter, K. A. (1973). Traumatic choroidal rupture with late serous detachment of the macula. Archives of Ophthalmology, 89, 354-355.

Gass, J. D. M. (1967). Pathogenesis of disciform detachment of the neuroepithelium. VI. Disciform detachment secondary to heredo-degenerative, neoplastic and traumatic lesions of the choroid. American Journal of Ophthalmology, 63, 689-711.

Gass, J. D. M. (1970). Stereoscopic Atlas of Macular Disease, 1st edn, p. 96. Mosby: St Louis.

Gitter, K. A., Slusher, M., and Justice, J. (1968). Traumatic haemorrhagic detachment of retinal pigment epithelium. Archives of Ophthalmology, 79, 729-732.

Harrington, D. O. (1964). The Visual Fields. A Textbook and Atlas of Clinical Perimetry, 2nd edn, p. 170. Mosby: St Louis.

Hart, J. C. D., and Frank, H. J. (1975). Retinal opacification after blunt non-perforating concussion injuries to the globe: a clinical and fluorescein angiographic study. Transactions of the Ophthalmological Societies of the United Kingdom, 95, 94-100.

Maberley, A. L., and Carvounis, E. P. (1977). The visual field in indirect traumatic rupture of the choroid. Canadian Journal of Ophthalmology, 12, 147-154.

Neame, H. (1940). Multiple ruptures of the choroid with retention of good vision. British Journal of Ophthalmology, 24, 399-400.

Reed, H., and Drance, S. M. (1972). The Essentials of Perimetry, Static and Kinetic, 2nd edn, p. 160. Oxford Medical Publications: London.

Sipperley, J. O., Quigley, H. A., and Gass, J. D. M. (1978). Traumatic retinopathy in primates. The explanation of commotio retinae. Archives of Ophthalmology, 96, 22672273.

Smith, R., Kelly, J. S., and Harbin, T. S. (1974). Late macular complications of choroidal ruptures. American Journal of Ophthalmology, 77, 650-658.

Traquair, H. M. (1949). An Introduction to Clinical Perimetry, 6th edn, p. 96. Kimpton: London.

Yanoff, M., and Fine, B. S. (1975). Ocular Pathology: $A$ Text and Atlas, p. 151. Harper and Row: Hagerstown, Maryland. 